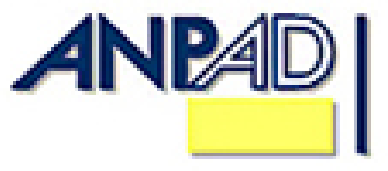

Disponível em

http://www.anpad.org.br/rac

RAC, Rio de Janeiro, v. 16, n. 3, art. 4, pp. 397-417, Maio/Jun. 2012

$($ (c) EY-NG

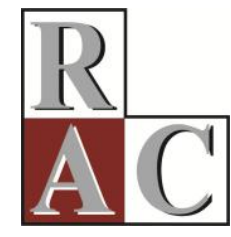

\title{
O Processo Decisório Descrito pelo Indivíduo e Representado nos Sistemas de Apoio à Decisão
}

\section{The Decision Making Process as Described by Individuals and Represented in Decision Support Systems}

Eliete dos Reis *

E-mail: elietedosreis@gmail.com Universidade Federal de Santa Maria - UFSM Santa Maria, RS, Brasil.

Mauri Leodir Löbler E-mail: lobler@ccsh.ufsm.br Universidade Federal de Santa Maria - UFSM Santa Maria, RS, Brasil.

Copyright (C) 2012 RAC. Todos os direitos, até mesmo de tradução, são reservados. É permitido citar parte de artigos sem autorização prévia, desde que seja identificada a fonte. 


\title{
Resumo
}

Este estudo teve como objetivo verificar se um Sistema de Apoio à Decisão (SAD) reproduz o processo de decisão humana. Para isso, tomaram-se, como base, os elementos fundamentais do método Processo Analítico Hierárquico (AHP), de Saaty (1991), que permitiu constituir cinco categorias de análise. Assim, por meio de um experimento em laboratório, foi realizada a tarefa de escolha de notebook sob duas maneiras: com e sem auxílio de um SAD, no qual foi utilizado o protocolo verbal think aloud, tendo somente a mente do indivíduo como guia da decisão. A apresentação dos resultados exibiu diferença significativa para quatro das cinco categorias de análise. Por meio dos testes de hipóteses, a única categoria que não teve diferença significativa em ambas as tarefas foi a ordem de escolha dos critérios. Com relação às demais categorias, não foi encontrada comprovação estatística para afirmar que o processo se assemelha ao processo de decisão com o auxílio de um SAD, embora o resultado final da decisão tenha sido o mesmo. Por tal razão, a hipótese deste estudo não pode ser confirmada, não sendo possível afirmar que um SAD reproduz o processo de decisão humana. Com relação ao comportamento do decisor, sobre as opções de busca de informações, pode-se dizer que o processo se assemelha em ambas as tarefas, uma vez que o decisor buscou as informações por critério.

Palavras-chave: processo decisório; métodos multicritério de apoio à decisão; think aloud.

\begin{abstract}
This study aimed to check if a Decision Support System (DSS) reproduces the process of human decision. For this, we used the fundamental elements of the Saaty's (1991) Analytic Hierarchy Process (AHP), which allows up to five categories of analysis. Accordingly, through a laboratory experiment enacted the task of choosing a notebook in two different ways: with the aid of a DSS; and without the aid of the system, and only the individual's mind to guide the decision while using a think aloud protocol. The results showed significant differences for four of the five categories of analysis. Through hypothesis testing, the only category that had no significant difference in both tasks was the order of choice criteria. Regarding the other categories, statistical evidence did not support the idea that the processes are similar, even if the final decision was the same. For this reason, this study's hypothesis was not confirmed; it is not possible to say that a DSS reproduces the human decision-making process. Regarding the conduct of the decision-maker concerning options for finding information, the process is similar in both tasks, since the decision-maker sought information according to criteria.
\end{abstract}

Key words: decision making; multiple-criteria methods for decision support; think aloud methodology. 


\section{Introdução}

Em razão de a sociedade estar se tornado cada vez mais complexa, há a necessidade de equilibrar objetivos conflitantes e de tomar decisões com múltiplos critérios. Dessa forma, o tema decisão tem atraído a atenção de muitos pensadores, como Chen (2006), porque tudo o que se faz, consciente ou inconscientemente, é resultado de alguma decisão (Saaty, 2008).

O processo decisório é complexo e, em certas situações, é preciso seguir alguns critérios para que se possa escolher uma entre as diferentes alternativas sob consideração (Gomes, Araya, \& Carignano, 2004). Assim, alguns modelos foram desenvolvidos a fim de sintetizar os principais mecanismos que orientam o processo decisório, como, o modelo de decisão de Simon, mais comumente conhecido como modelo das fases de decisão.

Além desses modelos, o desenvolvimento e a aplicação de metodologias que permitam ao decisor ponderar com eficiência os diferentes critérios, usados na tomada de decisão de problemas complexos, têm sido apresentados como auxílio na tomada de decisão (Gomes et al., 2004). Um exemplo dos vários métodos multicritério de apoio à decisão, é o método Processo Analítico Hierárquico (AHP), de Saaty (1991), que, assim como outros modelos, objetiva reproduzir o raciocínio humano no que diz respeito à comparação de elementos de um conjunto. Tal processo utiliza uma escala de importância para confrontar os elementos par a par (Carvalho \& Mingoti, 2005).

Não obstante os modelos do processo decisório e as metodologias multicritério de apoio à decisão, é importante ponderar que o indivíduo faz uso, frequentemente, de um modelo mental de decisão, ou seja, uma descrição de como interpreta determinada situação. Dessa forma, a maneira como as pessoas podem e tomam decisões varia consideravelmente (Dillon, 1998).

Para Dillon (1998), pesquisas têm focado a forma como as decisões são tomadas e o modo por que, teoricamente, deveriam ser tomadas; como consequência, o alcance e a diversidade da teoria tem sido vastos. Dependendo de sua base metodológica, esses modelos podem ser classificados como descritivos, prescritivos ou normativos. De maneira simplificada, segundo Bell, Raiffa e Tversky (1988), os modelos descritivos abordam o processo decisório como ele é, e os modelos prescritivos ou normativos abordam o processo decisório como ele deveria ser.

Diante dessas considerações e da relevância que o processo de tomada de decisão exerce sob diferentes alternativas, foram realizadas investigações a fim de verificar se um Sistema de Apoio à Decisão (SAD) reproduz o processo de decisão humana.

Para concepção deste trabalho, fizeram-se estudos sobre metodologias multicritério de apoio à decisão, abordagens prescritivas e normativas em processo decisório e sobre o método de protocolo verbal - Think Aloud - ou pensar em voz alta. Este trabalho também contou com a aplicação de uma tarefa que simulava a compra de notebook, na qual os decisores, por meio de um experimento, poderiam resolvê-la com ou sem o auxílio de um sistema de apoio à decisão. Na sequência dessas abordagens, este estudo resgata alguns dos resultados obtidos em outro realizado no ano de 2010, parte da pesquisa de uma dissertação de mestrado (Reis, 2011) sobre processo decisório. As considerações finais deste versam a respeito do mapeamento do processo decisório quando o indivíduo resolve uma tarefa com e sem o auxílio de um SAD. 


\section{Referencial Teórico}

\section{Metodologia multicritério de apoio à decisão}

Problemas complexos de tomada de decisão, nos quais vários critérios podem tornar-se necessários para uma escolha final, são comuns em uma infinidade de áreas. Dessa forma, o desenvolvimento e a aplicação de metodologias que permitem ao decisor ponderar com eficiência os diferentes critérios usados na tomada de decisão são recursos que vêm facilitando a escolha do decisor (Gomes et al., 2004).

Esses métodos evoluíram da Pesquisa Operacional (Martel, 1999) e têm como objetivo auxiliar no processo de escolha, na ordenação e na classificação das alternativas, bem como incorporar múltiplos aspectos no processo decisório (Ensslin, Montibeller, \& Noronha, 2001). Gomes, Araya e Carignano (2004) afirmam que uma metodologia multicritério de apoio à decisão procura fazer com que o processo seja mais neutro, objetivo, válido e transparente possível, sem a pretensão de mostrar ao decisor uma solução única e verdadeira, mas sim auxiliar na escolha da decisão.

Neste contexto, a metodologia multicritério possui dois grandes ramos: (a) o ramo contínuo da decisão multicritério, conhecido como programação multiobjetivo, o qual se ocupa com problemas com objetivos múltiplos, em que as alternativas podem adquirir um número infinito de valores; e (b) o ramo discreto ou Decisão Multicritério Discreta (DMD), que analisa problemas nos quais o conjunto de alternativas de decisão é formado por um número limitado e, na maioria das vezes, pequeno de variáreis (Gomes et al., 2004; Zanakis, Solomon, Wishart, \& Dublish, 1998).

Destaca-se, ainda, a relevância das correntes de pensamento instituídas nesse campo de pesquisa, pois, conforme Roy (1996), há duas escolas de pensamento claramente distintas: a Escola Europeia, fundada por Bernard Roy, que promoveu o conceito de outranking, para avaliar alternativas discretas, e a Escola Americana, inspirada no trabalho de Keeney e Raiffa, que se refere a funções de valores multiatributos e à Teoria da Utilidade Multiatributo.

Vários métodos multicritérios de apoio à decisão surgiram a partir dessas correntes de pensamento, dentre eles o método de análise hierárquica (AHP - do inglês Analytic Hierarchy Process), modelo subjacente ao sistema de apoio à decisão do presente estudo. O AHP, criado por Thomas Saaty em 1980, foi um dos primeiros métodos da Escola Americana, desenvolvidos para solucionar problemas de decisão com múltiplos critérios, quantitativos e qualitativos (Gomes, 2007). O AHP permite estruturar uma decisão em níveis hierárquicos, determinando, por meio da síntese de valores dos decisores, uma medida global para cada uma das alternativas, priorizando-as ou classificando-as ao final do método (Saaty, 1991).

Nesse contexto, com base nesses métodos, é possível desenvolver sistemas de apoio à decisão baseados em computador, que auxiliam os usuários em atividades de julgamento e escolha. Segundo Druzdzel e Flynn (2002), esses sistemas são ferramentas poderosas de integração de métodos científicos no auxílio de decisões complexas, com técnicas desenvolvidas na ciência da informação. Para esses autores, os Sistemas de Apoio à Decisão (SAD) não substituem os seres humanos, mas aumentam a sua capacidade limitada para lidar com problemas complexos. A interface do usuário determina se um SAD será utilizado na sua totalidade e, em caso afirmativo, se a qualidade final das decisões será maior do que quando o decisor não utiliza um sistema de apoio à decisão.

Tendo realizado uma discussão sobre metodologias multicritério de apoio à decisão com ênfase no Processo Analítico Hierárquico (AHP), modelo subjacente ao sistema de apoio à decisão do presente estudo, apresentam-se, na sequência, os modelos prescritivos e normativos em processo decisório. 


\section{Modelos prescritivos e descritivos em processo decisório}

A maneira como as pessoas podem tomar decisões e tomam-nas varia consideravelmente. Há pouco tempo, algumas pesquisas têm focado a forma em que as decisões são tomadas e o modo pelo qual, teoricamente, deveriam ser tomadas. Como consequência, o alcance e a diversidade da teoria tem sido vasta (Dillon, 1998). A partir disso, surgiu uma matriz de modelos de tomada de decisões. Dependendo de sua base metodológica, esses modelos podem ser classificados como descritivos, prescritivos ou normativos. Dessa forma, a modelagem prescritiva e a modelagem descritiva foram alvo de muitos autores sobre processo decisório, dentre os quais se destacam Bell et al. (1988), Rapoport (1994) e Stanovich e West (1999).

De acordo com Hansson (1994), a teoria da decisão normativa é uma teoria sobre como as decisões devem ser tomadas. Diz como um ator racional deverá agir para decidir, em certas condições, precisamente definidas, envolvendo escolha de ações ou alternativas. A teoria descritiva é uma teoria sobre como decisões são realmente feitas (Hansson, 1994) e propõe-se a descrever como um ator real se comporta ou, durante o tempo, como irá se comportar em situações que, supostamente, poderão ser descritas de maneira suficientemente precisas.

Bell et al. (1988) propuseram uma abordagem mais ampla sobre esta temática, dividindo-a em três modelos ou teorias: abordagem descritiva, abordagem normativa e abordagem prescritiva. Segundo esses autores, normalmente dividiam-se as abordagens em descritiva e normativa, sendo esta última utilizada como sinônimo de prescritiva. Os autores descrevem, de maneira bastante objetiva e simples, os modelos normativos e descritivos como representando, respectivamente, o deve e o é.

Na verdade, a grande contribuição de Bell et al. (1988) é o modo como abordam os três modelos, apresentando-os não como antagônicos, mas sim como complementares. Em uma primeira explicação simplificada, pode-se dizer que modelos descritivos abordam o processo decisório como ele é, e os modelos normativos abordam o processo decisório como ele deveria ser. Os autores propõem, de uma maneira geral, que uma análise prescritiva explica algumas das consequências lógicas da teoria normativa e os resultados empíricos dos estudos descritivos.

Bell et al. (1988) definem análise descritiva como a abordagem de mais fácil entendimento. Introduzem a definição afirmando que a abordagem descritiva relaciona-se a como o indivíduo pensa e se comporta e a como os indivíduos aprendem e modificam seu comportamento, ou seja, o que os indivíduos afirmam sobre suas percepções e escolhas. Em suma, a análise descritiva diz respeito a como e por que as pessoas pensam e agem de determinada forma. É uma atividade altamente empírica e clínica, que se enquadra diretamente no campo da ciência social, relacionado ao comportamento individual.

Quanto à teoria normativa, Bell et al. (1988) afirmam que há uma noção de que teoria normativa refere-se ao modo como o ser humano idealizado, racional, superinteligente, deve agir. A marca oficial das análises normativas são coerência e racionalidade como normalmente capturadas em termos de aspirações, precisamente especificadas, ou axiomas de forma. Visualizando a teoria descritiva e normativa como dois extremos, num mesmo continuum, num ponto intermediário, a partir de uma interpretação de Bell et al. (1988), encontra-se a modelagem prescritiva. A modelagem prescritiva aborda o que o indivíduo deveria fazer para melhorar suas escolhas, de que maneiras deveria pensar, quais seriam os auxílios decisórios, que esquemas conceituais seriam úteis - não para idealização, mitização ou automação, mas para pessoas reais.

Resumindo as três abordagens pelos critérios com que cada uma pode ser avaliada, diz-se que o modelo descritivo será avaliado pela sua validação empírica; o modelo normativo, por sua adequação teórica; e o modelo prescritivo, por seu valor pragmático e pela sua capacidade de auxiliar as pessoas a tomarem melhores decisões (Bell, Raiffa, \& Tversky, 1988).

Com base nas definições e comentários apresentados pelos autores, busca-se entender qual a modelagem apropriada para um trabalho em processo decisório. Clemen (1995) afirma que uma razão 
óbvia para estudar análise decisória é a melhoria das decisões e que o objetivo de analisar decisões é auxiliar o decisor a abrir seus olhos. Neste sentido, o estudo do processo decisório, neste trabalho, deve utilizar uma modelagem descritiva como a definida por Bell et al. (1988).

Nesta seção, apresentaram-se algumas definições sobre modelos prescritivos e descritivos em processo decisório, no intuito de elucidar qual a modelagem apropriada para estudos nesta área. A próxima seção descreverá os procedimentos metodológicos adotados para o alcance dos objetivos delineados neste estudo, apresentando o desenho, a tarefa experimental, as hipóteses, bem como os sujeitos que participaram da pesquisa.

\section{Procedimentos Metodológicos}

\section{Desenho experimental}

Para consecução deste trabalho, desenvolveu-se o método de pesquisa experimento em laboratório. Este, de acordo com Sampieri, Collado e Lucio (2006), consiste numa situação de controle, na qual se manipulam, de maneira intencional, uma ou mais variáveis independentes, a fim de se analisarem as consequências dessa manipulação sobre uma ou mais variáveis dependentes. $\mathrm{O}$ modelo de decisão, proposto por um Sistema de Apoio à Decisão (SAD), constitui-se na variável independente, e o resultado da decisão 1 e 2 do sujeito experimental, no final da tarefa, compõe a variável dependente. $\mathrm{O}$ modelo de pesquisa pode ser visualizado na Figura 1.

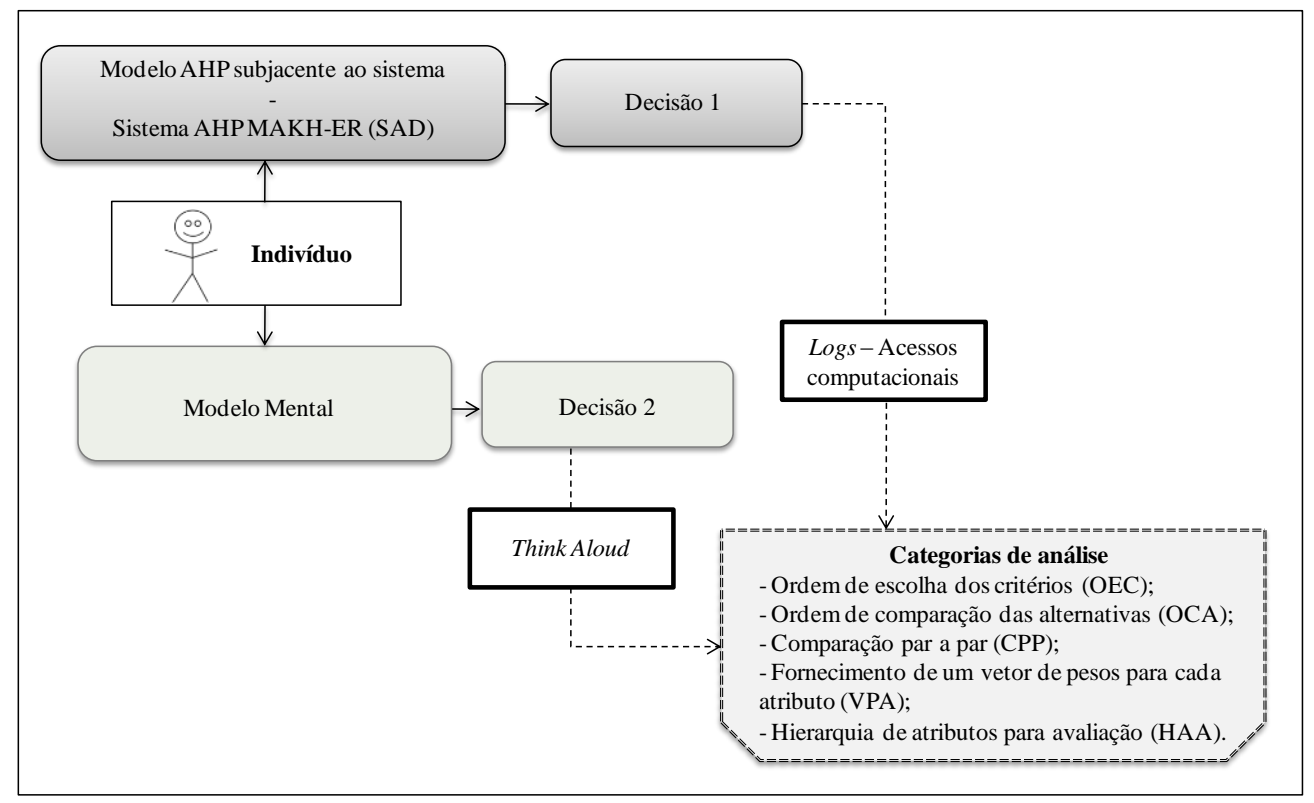

Figura 1. Modelo de Pesquisa.

Os resultados da decisão são medidos a partir da escolha final dos indivíduos, por meio da utilização dos $\log s$, ou de acessos computacionais gerados pelo sistema para a tarefa com auxílio do $\mathrm{SAD}$, e do método de coleta de dados protocolo verbal think aloud, para a tarefa sem o auxílio do SAD. É importante mencionar que, baseado nos elementos fundamentais do método Processo Analítico Hierárquico (AHP), os resultados da decisão permitiram constituir as cinco categorias de análise deste estudo: Ordem de Escolha dos Critérios (OEC), Ordem de Comparação das Alternativas (OCA), Comparação Par a Par (CPP), Fornecimento de um Vetor de Pesos para cada Atributo (VPA) e Hierarquia de Atributos para Avaliação (HAA). 


\section{A tarefa experimental e as hipóteses do estudo}

A tarefa experimental, utilizada neste estudo, constitui-se na simulação de compra de notebook para uso pessoal, possuindo, como alternativas, três modelos de aparelhos, escolhidos entre os publicados nas revistas Coleção Info e Info Exame, de 2008. Como atributos/critérios, observaram-se as características dos notebooks, que são a base para a tomada de decisão. Os oito critérios velocidade do processador, memória RAM, espaço de armazenamento do HD, tamanho da tela, peso, dimensão, marca, assistência técnica autorizada e preço - foram definidos com base em estudos anteriores de McMullen e Tarasewich (2000), Vieira e Slongo (2006) e de revistas especializadas. O critério de manutenção foi definido, por especialistas da área, como determinante para o bom funcionamento do notebook.

A fim de atingir o objetivo proposto, o experimento foi conduzido de forma que o indivíduo realizasse uma tarefa decisória de modo independente: (a) com o auxílio de um Sistema de Apoio à Decisão (SAD); e (b) sem o auxílio do SAD, ou seja, pelo modelo mental de decisão, no qual foi mapeado esse processo através da utilização do protocolo verbal think aloud, ou pensar em voz alta. Segundo Norman (1983), os modelos mentais são usados para caracterizar as formas pelas quais as pessoas compreendem os sistemas físicos com os quais interagem. Eles servem para explicar o comportamento do sistema, fazer previsões, localizar falhas e atribuir causalidade aos eventos e fenômenos observados. Na visão de Borges (1998), o que parece fundamental, nas várias concepções do conceito de modelo mental, é a ênfase na ideia de rodar o modelo na imaginação. Isso permite ao usuário falar sobre situações passadas e futuras, permitindo que ele tome decisões, faça previsões e inferências sobre o comportamento futuro do sistema representado.

Assim, a hipótese principal deste trabalho postula que o processo de tomada de decisão em uma tarefa, utilizando um sistema de apoio à decisão, é o mesmo de quando não se utiliza um sistema de apoio à decisão. A partir da hipótese principal, apresentam-se as hipóteses secundárias, a seguir:

H1: a ordem de escolha dos critérios é a mesma no processo de decisão em uma tarefa, utilizando ou não um SAD;

H2: a ordem de comparação das alternativas é a mesma no processo de decisão em uma tarefa, utilizando ou não um SAD;

H3: as comparações par a par são as mesmas no processo de decisão em uma tarefa, utilizando ou não um SAD;

H4: a intensidade de pesos atribuída para cada atributo no processo de decisão em uma tarefa é a mesma, utilizando ou não um SAD;

H5: a estruturação da hierarquia de atributos para avaliação é a mesma no processo de decisão em uma tarefa, utilizando ou não um SAD;

H6: o resultado da decisão, utilizando ou não um SAD, em uma tarefa é o mesmo.

\section{Tarefa experimental com o auxílio de um SAD}

Para a execução da tarefa com o auxílio do SAD, foi disponibilizado ao decisor o software AHP MAKH-ER, validado em estudo anterior por Corso e Löbler (2010), baseado no método Processo Analítico Hierárquico (AHP). Este permite estruturar uma decisão em níveis hierárquicos, determinando, por meio da síntese de valores dos decisores, uma medida global para cada uma das alternativas, priorizando-as ou classificando-as ao final do método (Saaty, 1991). Cabe salientar que a opção por esse modelo é em decorrência da importância que o mesmo exerce na tomada de decisão. De acordo com Saaty (1991), o AHP é baseado na capacidade humana inata para fazer julgamentos em relação a pequenos problemas. Assim, o método tem sido usado, com sucesso, em uma variedade de países sob uma ampla gama de aplicações, desde o gerenciamento de projetos (Al-Harbi, 2001); 
decisão estratégia de TI (Murakami, 2003); avaliação de fornecedores a partir da aplicação de critérios ambientais (Handfield, Walton, Sroufe, \& Melnyk, 2002), estudos na área da saúde (Liberatore \& Nydick, 2008) até a decisão do modal de transporte logístico (Özceylan, 2010).

A Figura 2 representa a segunda tela do AHP MAKH-ER, na qual o decisor resolve a tarefa. Como se pode observar, essa tela apresenta um layout com a seguinte disposição: nas três linhas, estão os modelos dos notebooks que serviram como alternativas para escolha e, nas colunas, estão os atributos de cada notebook, que são a base para a tomada de decisão. As células contêm as informações da alternativa $\mathrm{x}$ critério e, conforme o decisor vai clicando nas células, sem ordem previamente estabelecida, as informações vão aparecendo, ficando ao seu critério quais informações quer verificar primeiro. Assim que o decisor examina todos os valores das alternativas de um critério qualquer, é aberta uma tela automática, do tipo pop up, com uma pergunta, questionando-o a fazer uma comparação par a par de cada elemento, conforme metodologia AHP. Dessa forma, o decisor irá representar, de acordo com uma escala pré-definida por Saaty (1991), sua preferência entre os elementos que está comparando.

O exemplo da Figura 2 demonstra que o decisor deverá comparar o critério velocidade do processador para o modelo de notebook Pavilion DV 1110BR versus o modelo Vaio NW210AE. Ainda, através da comparação par a par, esse critério deverá ser comparado para os demais modelos de notebook. Essa comparação é feita quando o decisor responde à pergunta: no critério velocidade do processador, qual a maior importância? Na sequência, o decisor também deverá responder a outra pergunta: qual a intensidade dessa importância? Ou seja, quantas vezes o critério velocidade do processador do modelo Vaio NW210AE é mais importante que a velocidade do processador do modelo Pavilion DV 1110BR.

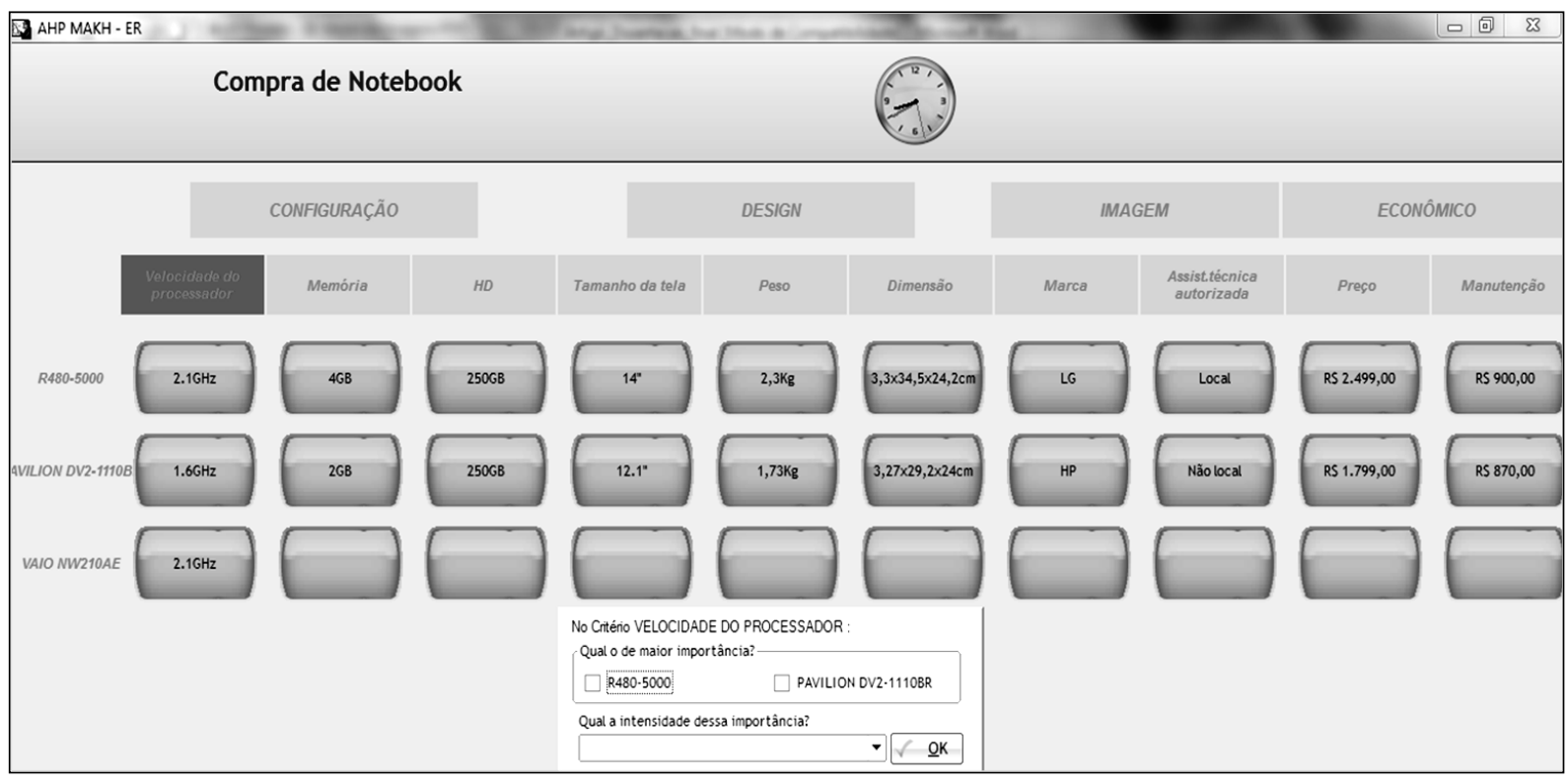

Figura 2. Tela da Tarefa do AHP MAKH-ER - com Abertura da Tela de Julgamento no Primeiro Nível.

Fonte: Sistema desenvolvido para a pesquisa.

As opções de respostas das alternativas são baseadas na escala fundamental de números absolutos de Saaty (2008), o qual entende que, para fazer comparações, na segunda fase do método, é necessária uma escala de números que varia de 1 a 9 . Conforme esse autor, a escala de números indica quantas vezes mais um elemento é importante ou dominante sobre outro elemento, que diz respeito ao critério ou propriedade em relação aos quais estão sendo comparados.

O processo da tela automática, do tipo pop up, repete-se até o decisor avaliar todos os critérios dentro do mesmo grupo. Após, uma nova tela de pop up de comparação é aberta para um nível 
hierárquico superior. Nela, a comparação é realizada entre os critérios do grupo, por exemplo, velocidade do processador x memória RAM, para, finalmente, fazer a comparação no último nível hierárquico, ou seja, entre os grupos de critérios, por exemplo, grupo de critério configuração x grupo de critério imagem. Por fim, obtêm-se os pesos e checa-se a consistência da matriz, processo denominado de normalização da matriz (Saaty, 1991). A escolha da decisão final deverá basear-se naquela alternativa que obtenha o maior escore (peso percentual), que é apresentada em forma de gráfico na última tela do sistema.

\section{Tarefa experimental sem o auxílio de um SAD}

Para a execução da tarefa sem o auxílio de um $\mathrm{SAD}$, na qual o sujeito experimental a resolve livremente, sem o uso de um modelo pré-estabelecido, foi utilizado o método de protocolo verbal think aloud, no qual, segundo Ericsson e Simon (1993), o indivíduo verbaliza seus pensamentos sem descrever ou explicar o que está fazendo - ele simplesmente verbaliza as informações em que presta atenção ao gerar a resposta durante a resolução de um problema. Para esses autores, o método think aloud recorre a pensamentos sobre assuntos que estão na memória de curto prazo. Como todos os processos cognitivos ocorrem na memória de curto prazo, o pensamento consciente do sujeito pode ser relatado no momento em que é processado. Os processos cognitivos que geram verbalizações (pensar em voz alta) são um subconjunto dos processos cognitivos que geram o comportamento ou ação.

Dessa forma, o método de coleta de dados protocolo verbal pressupõe uma série de condições e precauções que o pesquisador deve tomar para o seu uso efetivo. Dentre esses critérios estão a seleção dos sujeitos participantes da pesquisa; a escolha da tarefa a ser desempenhada; o cenário onde a pesquisa será aplicada; as instruções que servirão como referência para os sujeitos executarem a tarefa; os procedimentos de registro, gravação e transcrição de protocolos; e, por fim, a identificação das categorias de análise.

Faz-se necessário mencionar que, para operacionalização da tarefa sem o auxílio do AHP MAKH-ER, as alternativas e os critérios com todas as informações relevantes foram disponibilizados aos indivíduos por meio de três fichas ilustrativas, cada uma contendo as informações relacionadas a uma alternativa/modelo de notebook. Além das fichas ilustrativas, os sujeitos experimentais receberam uma planilha com as descrições dos critérios utilizados na tarefa decisória, bem como lápis e papel, como material de apoio, caso julgassem necessário, para resolução da tarefa. O layout das fichas ilustrativas pode ser visualizado na Figura 3.

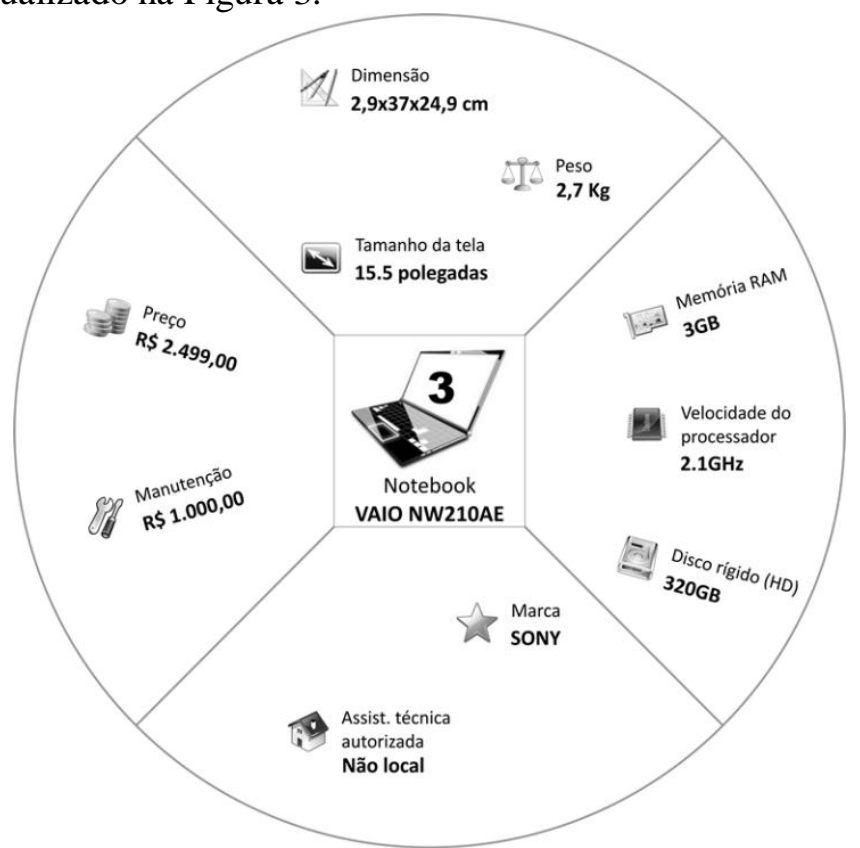

Figura 3. Ficha Ilustrativa com as Alternativas, Critérios e Valores dos Atributos. 
Com relação ao cenário ou ambiente de aplicação desta pesquisa, duas possibilidades de local foram apresentadas os sujeitos experimentais: (a) em laboratório no Programa de Pós-Graduação em Administração de uma Instituição Federal de Ensino, localizada no Rio Grande do Sul; e (b) no local de trabalho do indivíduo. Independente do local de aplicação combinado, os mesmos procedimentos foram adotados com todos os sujeitos experimentais.

As instruções para consecução da tarefa, segundo Someren, Barnard e Sandberg (1994), foram entregues em mãos aos sujeitos experimentais, usando uma comunicação clara e simples. A fim de evitar erros de interpretação de como o método funciona, as instruções foram lidas para os indivíduos, e realizou-se uma demonstração de como verbalizar os pensamentos durante o desempenho de uma tarefa, resolvendo um problema matemático, apresentado por Someren et al. (1994).

No tocante aos procedimentos de registro, Ericsson e Simon (1993) recomendam que os relatos do think aloud sejam gravados. Neste estudo, utilizou-se a técnica de gravação em formato digital de áudio. Após, todas as gravações foram transcritas e divididas em segmentos. Um segmento corresponde a uma unidade de informação em que foi prestada atenção (Ericsson \& Simon, 1993). Por conseguinte, foram realizadas as codificações dos protocolos de forma aleatória, selecionando um conjunto de dados e categorizando-os um de cada vez, sem um auxílio contextual dos segmentos anterior e posterior (Ericsson \& Simon, 1993).

Tendo em vista que as categorias de segmentação devem ser construídas levando-se em consideração o objetivo da investigação, tomou-se como base o método multicritério Processo Analítico Hierárquico (AHP), para estabelecimento das categorias de análise: OEC, OCA, CPP, VAP, HAA, constantes no modelo de pesquisa. Cabe salientar que ambas as tarefas foram realizadas pelos sujeitos experimentais sem restrição de tempo, ou seja, a tarefa poderia ser executada no tempo que o sujeito experimental julgasse necessário.

\section{Sujeitos experimentais}

Participaram da pesquisa, como sujeitos experimentais, indivíduos que possuem conhecimento sobre o objeto de decisão (notebook). Assim foram selecionados vinte indivíduos que se enquadram em algumas das seguintes características: atuam em áreas ligadas à informática, como assistentes técnicos, vendedores ou professores de cursos de informática, apreciadores de notebook ou assinantes de revistas especializadas em informática. Dessa forma, utilizou-se o critério de conhecimento do objeto para a seleção dos sujeitos que, conforme Löbler (2005), é uma variável influenciadora.

O experimento foi administrado individualmente com cada sujeito, no período de setembro a novembro de 2010 em um laboratório, com um computador e uma mesa de apoio, para a tarefa sem o auxílio do SAD. Cabe acrescentar que as tarefas foram aplicadas ao mesmo grupo experimental. Ou seja, os mesmos indivíduos participaram das duas condições, executando, primeiramente, a tarefa com o auxílio do $\mathrm{SAD}$ e, consequentemente, a tarefa sem o auxílio do sistema, sendo o resultado da decisão apresentado somente no final da resolução das duas tarefas. Neste caso, conforme Cozby (2003), temse um delineamento com medidas repetidas, no qual os mesmos indivíduos participam das duas condições, passando por repetidas mensurações da variável dependente, após cada condição experimental.

Esta seção tratou dos procedimentos metodológicos empregados para realização deste trabalho. Dessa forma, acredita-se que a escolha da tarefa experimental, do modelo multicritério de apoio à decisão subjacente ao SAD, bem como o protocolo verbal think aloud utilizados, representam um modelo metodológico com informações que se complementam. Assim, estas permitiram a aplicação da análise estatística no tratamento dos dados e subsídios para as conclusões do estudo. Na sequência, a próxima seção apresenta os resultados obtidos a partir da análise dos dados. 


\section{Análise dos Resultados}

A apresentação dos resultados contempla a análise do processo decisório e do comportamento do decisor, quando submetido à realização da tarefa, escolha de notebook, com e sem o auxílio de um sistema de apoio à decisão. Para tal, tomaram-se, como base, os elementos fundamentais do método Processo Analítico Hierárquico (AHP), que permitiram constituir as cinco categorias de análise deste estudo, apresentadas no modelo pesquisa.

Para a tarefa realizada com auxílio do AHP MAKH-ER, a análise das categorias foi possível por meio dos acessos computacionais $(\log s)$, gerados pelo sistema. Já para a tarefa realizada sem o auxílio do SAD, a análise foi possível por meio das categorias de segmentação geradas pelo protocolo verbal think aloud (pensar em voz alta). É relevante mencionar que as hipóteses secundárias deste estudo ajudaram a distribuir o argumento da hipótese principal e, dessa forma, serviram de base de resposta. Neste escopo são apresentados o comportamento do decisor e a análise do processo decisório.

\section{Comportamento do decisor: mapeando o processo de escolha}

De acordo com Löbler (2005), o mapeamento do processo decisório, ou traçado do processo, tem sido alvo de estudos há algum tempo, através de diferentes métodos como, por exemplo, análise de protocolo verbal (Ericsson \& Simon, 1993), método do traçado do processo através do estreitamento por fases (Levin \& Jasper, 1995), análise do movimento do olho humano (Lohse \& Johnson, 1996) e catalogação de acessos computacionais (Payne, Bettman, \& Johnson, 1993). Dessa forma, através de um breve relato, é apresentado o modo com que os indivíduos buscaram as informações no sistema e a análise do tempo de realização da tarefa em ambas as situações, quando o decisor teve o auxílio do SAD e quando não teve o auxílio do SAD.

No que se refere à tarefa com o auxílio do sistema, a ordem pela busca de informação no AHP MAKH-ER deu-se de acordo com o interesse do indivíduo, uma vez que, ao iniciar a tarefa, as informações só ficam disponíveis à medida que ele vai clicando nas células. $\mathrm{O}$ indivíduo tem, então, a opção de visualizar todas as informações dos critérios de uma alternativa, por exemplo, o valor da velocidade do processador, da memória RAM, do tamanho do HD, do tamanho da tela, do peso e assim por diante, para uma única alternativa de notebook. A Figura 4 demonstra um exemplo dessa opção.

A outra opção de visualização das informações é por critério, ou seja, o indivíduo visualiza primeiramente as informações das três alternativas de cada critério para então iniciar o processo de escolha. A Figura 5 demonstra um exemplo quando o indivíduo iniciou a busca de informações pelo critério de velocidade do processador. 


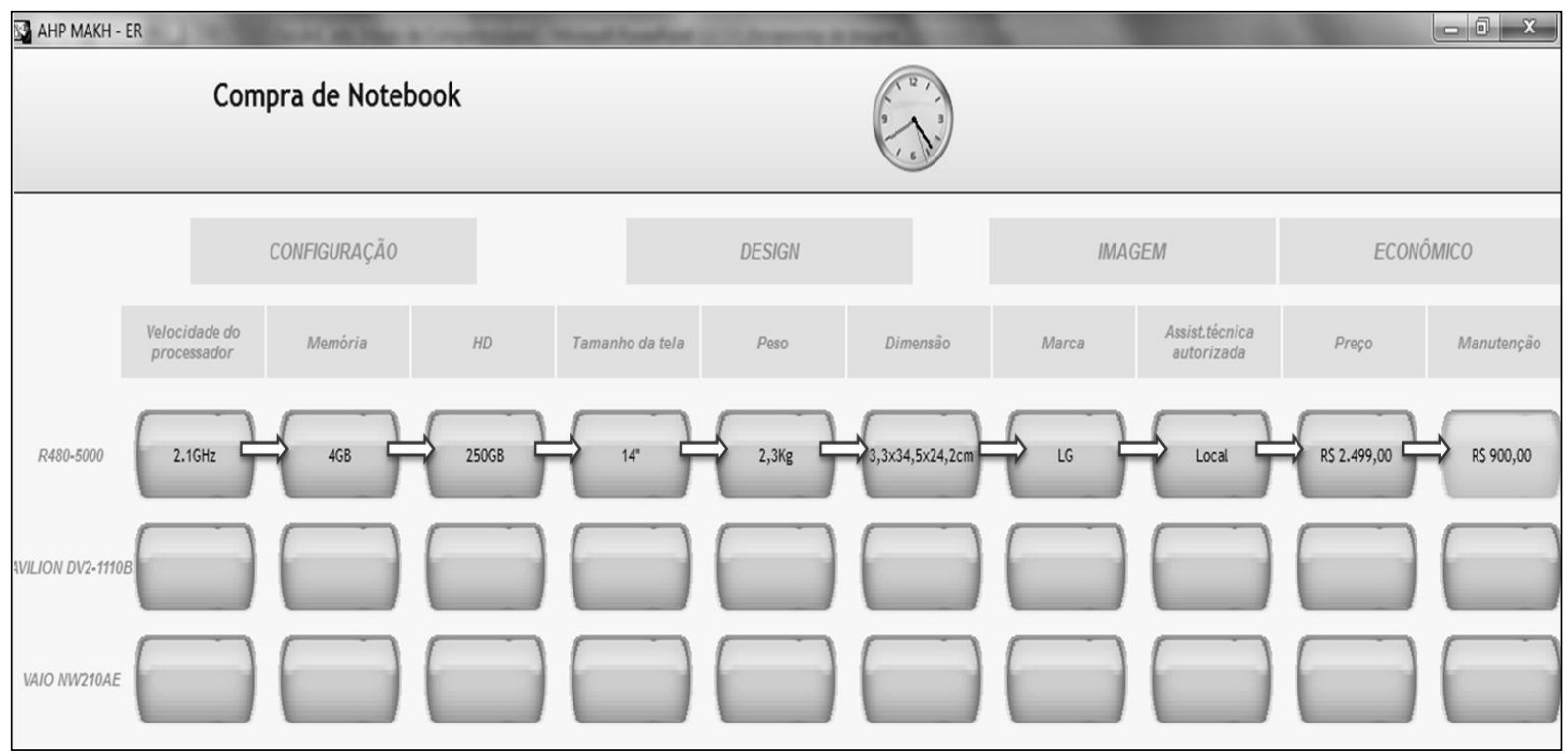

Figura 4. Busca da Informação por Alternativa.

Fonte: Sistema desenvolvido para a pesquisa.

Diante das possibilidades que tem o decisor de acessar as informações a partir dos logs do sistema, foi possível identificar que apenas cinco sujeitos utilizaram a primeira opção para busca de informações por alternativa e que os demais (quinze) se valeram da segunda opção para busca de informações por critério.

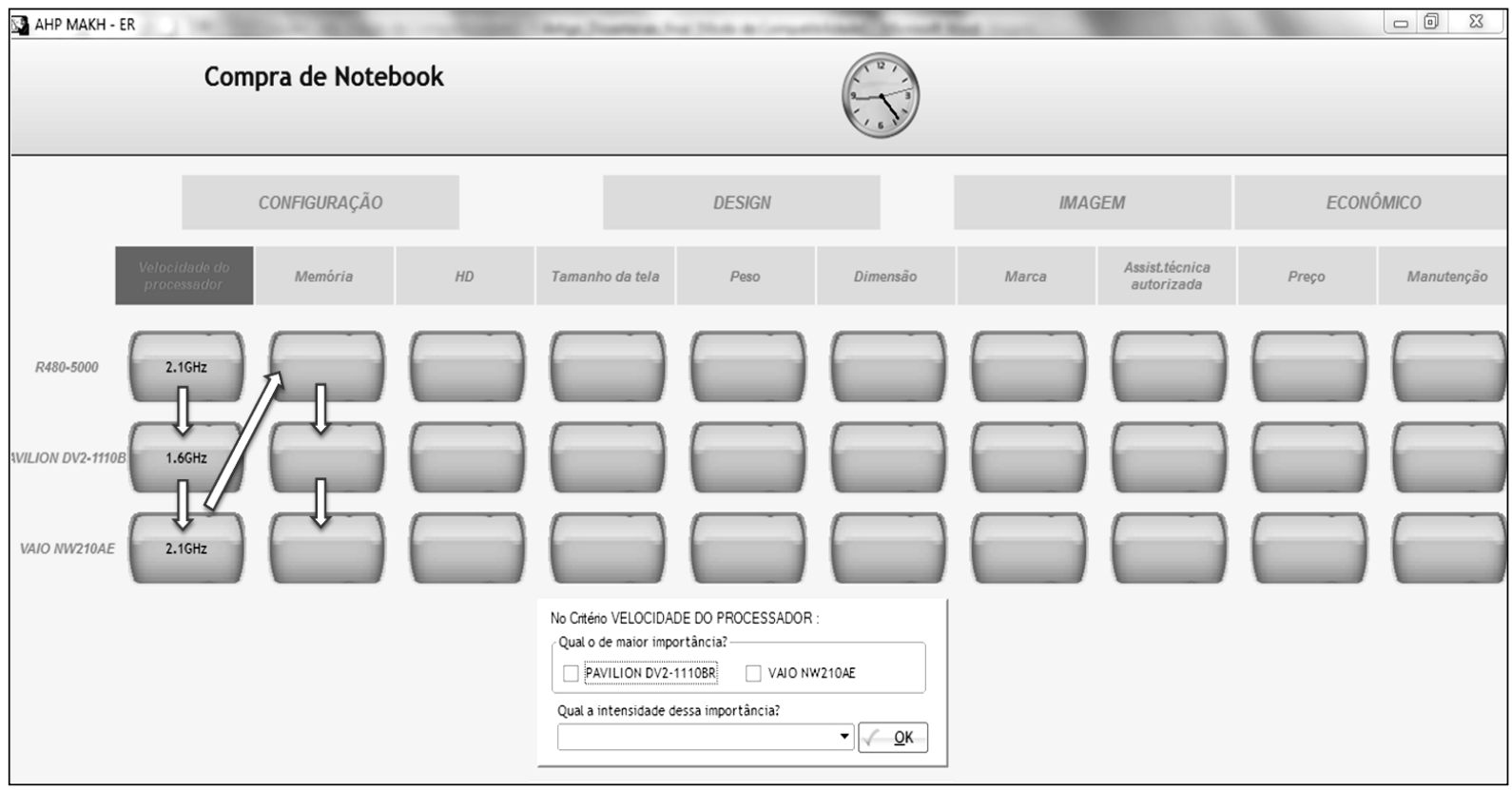

Figura 5. Busca da Informação por Critério.

Fonte: Sistema desenvolvido para a pesquisa.

Com base nesses resultados, observa-se que há certa tendência dos indivíduos em visualizar primeiro as informações das três alternativas para um critério. Isso pode estar associado ao fato de que o ser humano busca trabalhar com um menor número de variáveis possível, como uma forma de alívio do processo mental. Assim se explica a busca por critério, ou seja, são somente três atributos a considerar, enquanto que, por alternativa, são dez atributos. Outra vantagem da busca por critério é a possibilidade de comparar as alternativas, verificar o que realmente interessa ao decisor e escolher a melhor. 
Com relação à tarefa sem o auxílio do sistema, destaca-se que os sujeitos experimentais recebiam as três fichas ilustrativas juntamente com todas as informações disponíveis. Dessa forma, sem o auxílio de um método específico, como exemplo, eye-tracking ou análise do movimento do olho humano (Lohse \& Johnson, 1996), não há mecanismos para identificar quais informações o indivíduo visualizou primeiro. No entanto, após a transcrição e segmentação do protocolo verbal, foi possível evidenciar que a busca da informação foi similar à realizada no sistema, visto que o decisor verificou o valor das três alternativas para um determinado critério antes de fazer as ponderações para o atributo em questão.

Ampliando a análise do comportamento do decisor, observou-se o tempo de realização da tarefa em ambas as situações. Os dados apresentados na Tabela 1 permitem que se visualizem o tempo mínimo, o tempo máximo e o tempo médio de duração da tarefa quando o indivíduo utilizou um sistema de apoio à decisão e quando não utilizou o sistema de apoio à decisão.

Tabela 1

Tempo de Execução da Tarefa Escolha de Notebook

\begin{tabular}{ccc}
\hline Duração da tarefa em minutos & Tarefa com auxílio do SAD & Tarefa sem auxílio do SAD \\
\hline Tempo mínimo & $0: 06: 45$ & $0: 01: 43$ \\
Tempo máximo & $0: 22: 03$ & $0: 14: 00$ \\
Tempo médio & $0: 11: 45$ & $0: 06: 11$ \\
\hline
\end{tabular}

Observa-se que o menor tempo (um minuto e quarenta e três segundos) ocorreu na realização da tarefa sem o auxílio do SAD; e o maior tempo (quatorze minutos) ocorreu na tarefa com o auxílio do SAD. Com relação ao tempo médio, o maior também foi na realização da tarefa com o auxílio do sistema.

Outro aspecto a ser considerado é que, tanto o tempo mínimo quanto o tempo máximo de duração da tarefa sem o auxílio do sistema são inferiores ao tempo mínimo e máximo de duração da tarefa com o auxílio do sistema. Esse fato pode estar associado à condição de que, sem o auxílio do $\mathrm{SAD}$, o decisor ponderava os critérios que julgava de maior relevância, podendo não considerar, entretanto, todos os critérios. Consequentemente, o tempo de duração da tarefa sem modelo foi menor do que o da tarefa com modelo. Já na realização da tarefa com o auxílio do SAD, para obter o resultado da sua decisão, o indivíduo tinha de cumprir todas as etapas do sistema, justificando, então, a utilização de um tempo maior para escolha do notebook.

\section{Análise do processo decisório: entendendo como as pessoas decidem}

A fim de verificar se um SAD reproduz o processo de decisão humana, foram realizados testes estatísticos com relação às cinco categorias de análise oriundas do método AHP. Primeiramente, através do teste de Shapiro Wilk, testaram-se os dados, a fim de verificar se eles seguiam uma distribuição normal. Neste sentido, para as categorias OCA, CPP e VPA, que seguem uma distribuição normal, foi realizado o Teste $t$ de comparação das médias e, para as categorias OEC e HAA, que não seguem uma distribuição normal, foi aplicado o Teste dos Sinais. Ambos os testes foram realizados em um nível de significância de 5\%. A Tabela 2 apresenta os resultados obtidos para as categorias que seguem uma distribuição normal. 
Tabela 2

Teste $t$ para as Categorias de Análise OCA, CPP e VPA

\begin{tabular}{cccccc}
\hline $\begin{array}{c}\text { Categoria de } \\
\text { análise }\end{array}$ & N & $\begin{array}{c}\text { Com auxílio SAD } \\
\text { Média }\end{array}$ & $\begin{array}{c}\text { Sem auxílio SAD } \\
\text { Média }\end{array}$ & Teste $\boldsymbol{t}$ & Sig. \\
\hline OCA & 20 & 30,00 & 5,65 & 10,106 & 0,000 \\
CPP & 20 & 44,00 & 19,15 & 6,529 & 0,000 \\
VPA & 20 & 44,00 & 5,55 & 6,913 & 0,000 \\
\hline
\end{tabular}

Por meio da exposição dos resultados na Tabela 2, pode-se concluir que existem diferenças significativas para as três categorias analisadas quando o indivíduo resolve um problema auxiliado por um sistema de apoio à decisão do que quando resolve o problema livremente, pelo seu modelo mental.

Dessa forma, supõe-se que, neste estudo, o indivíduo, quando resolveu a tarefa livremente, sem o auxílio do AHP MAKH-ER, não seguiu a mesma ordem de comparação das alternativas de quando realizou a mesma tarefa com o auxílio do sistema.

Em termos de comparação par a par, a maneira como os indivíduos realizaram as comparações entre os critérios e os grupos de critérios das alternativas para a tarefa sem o auxílio do sistema não se assemelha às comparações realizadas através deste. Logo, o indivíduo não seguiu um processo padrão quando estava livre para escolher pelo seu modelo mental. Isto equivale a dizer que o decisor pode ter realizado comparações que não são sugeridas pelo sistema.

Quanto à intensidade de pesos dirigida a cada atributo no processo de decisão, é possível deduzir que os indivíduos, ao realizarem a tarefa livremente, ponderam, de maneira diferente, a intensidade de importância atribuída a cada critério, talvez por não terem um parâmetro, como a escala de números proposta por Saaty (1991), que indica quantas vezes mais um elemento é importante ou dominante sobre outro.

Os resultados acima apresentados podem estar associados ao fato de que, em situações em que o processo de tomada de decisão é realizado livre de um modelo, o indivíduo pondera somente o que julga relevante para a sua escolha. Nesse caso, ele não se dispõe a analisar e a avaliar critérios e alternativas que não o influenciarão. Por outro lado, em situações em que o processo de tomada de decisão é realizado seguindo um modelo preestabelecido, mediante um sistema, o indivíduo não tem a opção de excluir critérios e alternativas que julga não relevantes, pelo contrário, é necessário que analise e avalie todos os critérios e alternativas e execute todas as etapas do sistema para obter o resultado da sua decisão.

No que se refere às categorias que não seguem uma distribuição normal, OEC e HAA, segundo o que já foi mencionado neste texto, procedeu-se ao Teste dos Sinais, conforme pode ser observado na Tabela 3.

Tabela 3

Teste dos Sinais para as Categorias de Análise OEC e HAA

\begin{tabular}{cccccccc}
\hline $\begin{array}{c}\text { Categoria de } \\
\text { análise }\end{array}$ & $\begin{array}{c}\text { Diferença } \\
\text { Negativa }\end{array}$ & $\begin{array}{c}\text { Diferença } \\
\text { Positiva }\end{array}$ & Empate & Total & $\begin{array}{c}\text { Mediana } \\
\text { Com aux. } \\
\text { SAD }\end{array}$ & $\begin{array}{c}\text { Mediana } \\
\text { Sem aux. } \\
\text { SAD }\end{array}$ & Sig. \\
\hline OEC & 5 & 11 & 4 & 20 & 10,00 & 11,50 & 0,210 \\
HAA & 18 & 1 & 1 & 20 & 14,00 & 3,00 & 0,000 \\
\hline
\end{tabular}


Diante dos resultados expostos, é possível auferir que, das duas categorias analisadas, somente para a ordem de escolha dos critérios não houve diferença significativa quando o indivíduo resolveu a tarefa com o auxílio do sistema e sem ele. Ou seja, para essa categoria, o processo de tomada de decisão é similar. Isso pode ser em razão da importância atribuída a cada critério pelo decisor: por exemplo, se, para a compra de um notebook, o indivíduo julga de maior relevância os critérios de configuração (velocidade do processador, memória RAM e disco rígido), é bem provável que analise e avalie primeiro esses critérios, independente de estar auxiliado por um sistema ou não.

Cabe salientar que, para a categoria hierarquia de atributos para avaliação, houve diferença significativa quando o decisor resolveu a tarefa auxiliado pelo sistema: isso quer dizer que existe uma tendência do decisor hierarquizar somente os critérios ou grupos de critérios que julgar mais importantes. É provável que as hierarquizações não sigam o mesmo padrão do sistema, uma vez que este não permite ponderações. Por exemplo, entre um critério do grupo econômico versus um critério do grupo configuração, acontecimento observado no trecho do protocolo verbal de um dos sujeitos experimentais quando resolveu a tarefa sem o auxílio do sistema - "Sempre olhando o preço em relação à configuração, de novo" - segmento HAA44 de um dos sujeitos experimentais.

Além do teste de hipótese das cinco categorias de análise, realizou-se a prova do qui-quadrado $\left(x^{2}\right)$, a fim de verificar se o resultado da decisão, utilizando ou não um SAD em uma tarefa é o mesmo. Os resultados obtidos podem ser visualizados na Tabela 4.

Tabela 4

Teste Qui-quadrado do Resultado da Decisão

\begin{tabular}{cccc}
\hline Teste & R480-5000 & Pavilion dv21110br & Vaio nw210ae \\
\hline Qui-quadrado & 2,155 & 1,250 & 0,010 \\
& $\mathrm{p}=0,142$ & $\mathrm{p}=0,264$ & $\mathrm{p}=0,919$ \\
\hline
\end{tabular}

Por meio da análise dos dados constantes na Tabela 4, pode-se afirmar que estatisticamente, em um nível de significância de 5\%, não houve diferença significativa no resultado da decisão quando o indivíduo resolveu uma tarefa auxiliado por um SAD, ou não. Logo, o resultado final da decisão é o mesmo. Cabe salientar que o resultado final da decisão era apresentado ao indivíduo somente após a resolução de ambas as tarefas.

Com base nesses achados, é oportuno mencionar que, segundo Payne, Bettman e Johnson (1993), os exemplos mais marcantes no campo da decisão comportamental são as variações no modo de respostas do indivíduo frente a um problema de decisão. Nesse sentido, o fato de não haver diferença no resultado final da decisão pode ser associado ao princípio da invariância, proposto por Tversky e Kahneman (1986), os quais afirmam que não importa a maneira pela qual os problemas ou as opções sejam apresentados, pois eles serão interpretados do mesmo modo e, portanto, receberão os mesmos pesos. Dessa forma, sempre que se têm os mesmos elementos, é preciso chegar ao mesmo resultado de decisão final. Nesse sentido, embora o processo de escolha seja diferente, a decisão final é a mesma.

Frente ao que já foi exposto, é razoável deduzir que o processo de tomada de decisão, dentro de uma perspectiva normativa, utilizando um sistema de apoio à decisão, assimila-se apenas para a ordem de escolha dos critérios no que tange ao processo de decisão humana. Com relação às demais categorias de análise, originadas do modelo AHP, não foi encontrada comprovação estatística para afirmar que o processo seja semelhante. Dessa forma, a hipótese principal deste estudo não pôde ser corroborada. A Tabela 5 sumariza os resultados obtidos por meio do teste das hipóteses secundárias. 
Tabela 5

\section{Compilação do Teste das Hipóteses da Pesquisa}

\begin{tabular}{|c|c|c|}
\hline Hipótese & $\begin{array}{l}\text { Teste de } \\
\text { hipótese }\end{array}$ & Resultado encontrado na pesquisa \\
\hline $\begin{array}{l}\text { H1: A ordem de escolha dos critérios é a mesma } \\
\text { no processo de decisão em uma tarefa, } \\
\text { utilizando ou não um SAD. }\end{array}$ & Aceita & $\begin{array}{l}\text { A ordem de escolha dos critérios, utilizada } \\
\text { pelos decisores, foi semelhante em ambas as } \\
\text { tarefas. }\end{array}$ \\
\hline $\begin{array}{l}\text { H2: A ordem de comparação das alternativas é a } \\
\text { mesma no processo de decisão em uma tarefa, } \\
\text { utilizando ou não um SAD. }\end{array}$ & Rejeitada & $\begin{array}{l}\text { Ao compararem as alternativas de notebook } \\
\text { na tarefa sem o auxílio do SAD, os decisores } \\
\text { não seguiram a ordem estabelecida pelo } \\
\text { sistema. }\end{array}$ \\
\hline $\begin{array}{l}\text { H3: As comparações par a par são as mesmas no } \\
\text { processo de decisão em uma tarefa, utilizando } \\
\text { ou não um SAD. }\end{array}$ & Rejeitada & $\begin{array}{l}\text { Os decisores realizaram comparações par a } \\
\text { par na tarefa sem o auxílio do SAD, que não } \\
\text { eram sugeridas pelo sistema. }\end{array}$ \\
\hline $\begin{array}{l}\text { H4: A intensidade de pesos atribuída para cada } \\
\text { atributo no processo de decisão em uma tarefa é } \\
\text { a mesma utilizando ou não um SAD. }\end{array}$ & Rejeitada & $\begin{array}{l}\text { Na tarefa sem o auxílio do SAD, a } \\
\text { intensidade de pesos atribuída a cada } \\
\text { atributo foi diferente da sugerida pelo } \\
\text { sistema. }\end{array}$ \\
\hline $\begin{array}{l}\text { H5: A estruturação da hierarquia de atributos } \\
\text { para avaliação é a mesma no processo de } \\
\text { decisão em uma tarefa, utilizando ou não um } \\
\text { SAD. }\end{array}$ & Rejeitada & $\begin{array}{l}\text { Os decisores hierarquizaram atributos, na } \\
\text { tarefa sem o auxílio do } \mathrm{SAD} \text {, que não eram } \\
\text { sugeridos pelo sistema. }\end{array}$ \\
\hline $\begin{array}{l}\text { H6: O resultado da decisão, utilizando ou não } \\
\text { um SAD em uma tarefa, é o mesmo. }\end{array}$ & Aceita & $\begin{array}{l}\text { Os decisores escolheram a mesma } \\
\text { alternativa de notebook com e sem o auxílio } \\
\text { do sistema. }\end{array}$ \\
\hline
\end{tabular}

Dada a exposição dos resultados, é importante lembrar-se de que, até o momento, não foram encontrados, na literatura pesquisada, estudos sobre o fato de um sistema de apoio à decisão reproduzir o processo de decisão humana, o que torna relevante o trabalho em questão. Assim, as discussões acima incitam refletir sobre a questão normativa e descritiva do processo decisório, uma vez que, conforme Tversky e Kahneman (1986), há muitas evidências de que os indivíduos não seguem os modelos normativos de tomada de decisão e, como tal, não podem ser desconsiderados ou classificadas como pequenos desvios.

Esta seção abarcou a análise dos dados encontrados no experimento e os resultados do estudo com relação ao comportamento do decisor e ao tempo de realização da tarefa. A próxima seção abordará as considerações finais, sob a forma de uma conclusão, a qual traz algumas reflexões sobre a Teoria da Imagem.

\section{Considerações Finais}

A inquietude em relação à forma com que as decisões são tomadas e em que, teoricamente, deveriam ser tomadas, motivou a realização deste estudo, que teve como objetivo verificar se um sistema de apoio à decisão reproduz o processo de decisão humana. Dessa forma, por meio de um experimento em laboratório, foi realizada a tarefa de escolha de um notebook sob duas maneiras: com o auxílio de um sistema de apoio à decisão - AHP MAKH-ER - e sem o auxílio do SAD, pelo modelo mental de decisão, no qual foi utilizado o protocolo verbal think aloud.

A apresentação dos resultados exibiu diferença significativa para quatro das cinco categorias de análise decorrentes do método Processo Analítico Hierárquico (AHP), que foi a base para a análise 
deste estudo. Nesse sentido, por meio dos testes de hipótese, a única categoria que não teve diferença significativa em ambas as tarefas foi a Ordem de Escolha dos Critérios (OEC), ou seja, essa tarefa é a mesma no processo de decisão utilizando-se, ou não, um SAD.

As demais categorias: Ordem de Comparação das Alternativas (OCA), Comparação Par a Par (CPP), Fornecimento de um Vetor de Pesos para cada Atributo (VPA) e Hierarquia de Atributos para Avaliação (HAA) apresentaram diferença significativa em ambas as tarefas, podendo-se perceber que os decisores não seguiram o modelo prescrito pelo sistema. Assim, é possível deduzir que a ordem de comparação das alternativas e a ponderação dos critérios foram motivados pelo que os decisores julgavam mais relevante no momento da sua escolha. Com relação à atribuição da intensidade de peso, é plausível que tenha sido realizada de acordo com as informações e experiências que os decisores tinham acerca dos critérios e das alternativas que estavam sendo avaliadas. A própria hierarquização dos atributos pode ter sido em decorrência dos critérios que tiveram o maior impacto na escolha, não respeitando a ordem sugerida pelo sistema.

Neste escopo, a discussão dos resultados apresentados revela importantes particularidades no processo de tomada de decisão, uma vez que o processo decisório, dentro de uma perspectiva normativa, utilizando um sistema de apoio à decisão, assemelha-se apenas à ordem de escolha dos critérios no que tange ao processo de decisão humana. Com relação às demais categorias de análise, originadas do modelo Processo Analítico Hierárquico (AHP), não foi encontrada comprovação estatística para se afirmar que o processo seja semelhante, embora o resultado final da decisão tenha sido o mesmo. Por tal razão, a hipótese principal deste estudo não pôde ser confirmada, ou seja, não é possível afirmar, à luz da observação científica, que um sistema de apoio à decisão reproduza o processo de decisão humana.

Nesses termos, pode-se deduzir que a intensidade de percepção sobre cada etapa do processo de escolha, sem o auxílio do sistema, não é linear, pois há preponderância do objetivo principal dessa escolha, notebook para uso pessoal, seguido da análise dos atributos que o decisor julgar de maior relevância.

Além disso, a hipótese que testava se o resultado da decisão era o mesmo, utilizando-se ou não de um SAD em uma tarefa, foi aceita, de maneira que independente de o indivíduo estar auxiliado pelo sistema, o resultado final da sua decisão, neste estudo, foi o mesmo. Isso foi confirmado pelo princípio da invariância, advindo da teoria racional da decisão. O princípio da invariância, proposto por Tversky e Kahneman (1986), afirma que não importa a maneira pela qual os problemas ou as opções sejam apresentados, eles serão interpretados do mesmo modo e, portanto, receberão os mesmos pesos. Dessa forma, sempre que se têm os mesmos elementos, é preciso chegar ao mesmo resultado de decisão final.

Essas constatações podem ser explicadas pela Teoria da Imagem, que, segundo Dunegan (1995), é um modelo descritivo do processo de decisão, fundamentado em princípios psicológicos e sociológicos englobando os grandes paradigmas da decisão comportamental. Para esse autor, a Teoria da Imagem postula que o curso de ação na escolha do decisor dá-se em função da percepção de várias imagens que ele possui, incluindo a imagem de valor, de trajetória e estratégica. A imagem de valor refere-se aos princípios e crenças do decisor; a imagem da trajetória diz respeito aos objetivos e metas futuras do decisor; e a imagem estratégica consiste em planos e táticas do decisor para atingir seus objetivos.

Dessa forma, considerando a Teoria da Imagem, o decisor possui uma imagem de uma boa solução na sua mente e, no processo de decisão, ele procura uma solução que atinja o objetivo previamente estabelecido (Löbler, 2006). Por outro lado, quando o indivíduo tem o auxílio de um Sistema de Apoio à decisão, ele tende a ser mais racional, transformando um determinado critério em uma função de utilidade (Ensslin et al., 2001). Dessa forma, é possível descobrir uma solução ótima que se acredita existir. 
Cabem ainda comentários acerca do comportamento do decisor frente às opções de busca de informação. No AHP MAKH-ER, prevaleceu a opção para busca de informações por critério, na qual o indivíduo visualiza primeiro as informações das três alternativas para um critério para depois dar início as suas ponderações. Isso pode estar associado ao fato de que o ser humano busca trabalhar com um menor número de variáveis possíveis, como uma forma de alívio do processo mental. Quanto às opções de busca de informação, na tarefa sem o auxílio do AHP MAKH-ER, após a transcrição e segmentação do protocolo verbal, foi possível verificar que se assemelha à realizada no sistema, uma vez que os sujeitos experimentais verificavam o valor das três alternativas para um determinado critério, antes de fazerem as ponderações para o atributo em questão. Ainda é possível perceber, pela análise do protocolo verbal, que houve uma tendência, por parte dos sujeitos experimentais, em analisar primeiro os critérios do grupo configuração, ou seja, velocidade do processador, memória RAM e tamanho do HD.

No que tange ao tempo decorrido para a execução da tarefa, verificou-se que tanto o tempo mínimo quanto o tempo máximo de duração da tarefa sem o auxílio do sistema foram inferiores ao tempo mínimo e máximo de duração da tarefa com o auxílio do sistema. Esse fato pode estar associado à condição de que, sem o auxílio do $\mathrm{SAD}$, o decisor ponderava os critérios que julgava de maior relevância, podendo não considerar, entretanto, todos os critérios.

Adicionalmente ao que foi discutido até aqui, é importante que se teça um esboço das limitações deste estudo. Talvez a principal limitação seja em decorrência do tipo de pesquisa aplicada, que foi a experimental, tendo em vista a dificuldade de reproduzir situações da vida real, representada, neste estudo, pela simulação da compra de um notebook, mantendo o total controle das variáveis. Outra limitação foi a possibilidade de viés, provocada por efeitos de teste, pelo fato de os sujeitos experimentais serem submetidos a diferentes condições em uma sequência particular. Além desses, outro fator limitante foi o baixo número de sujeitos experimentais. Sugere-se, portanto, a replicação do estudo com uma quantidade maior de indivíduos e de estudos futuros que explorem o tema decisão sobre a abordagem aqui tratada. Uma opção seria a replicação do estudo em outro cenário, como, por exemplo, uma loja de eletrônicos, na qual o contexto é diferente, saindo de uma atividade hipotética para um cenário mais realista. Outro estímulo seria a utilização de outro sistema de apoio à decisão para verificar se um SAD reproduz ou não o processo de decisão humana. Sugere-se, ainda, a validação de um modelo no qual seja possível o decisor escolher somente os critérios que julgar de maior relevância para ponderação de suas análises ${ }^{(1)}$.

Artigo recebido em 20.06.2011. Aprovado em 07.02.2012.

\section{Nota}

${ }^{1}$ Trabalho apresentado no III Encontro de Administração da Informação (EnADI).

\section{Referências}

Al-Harbi, K. M. Al-S. (2001). Application of the AHP in project management. International Journal of Project Management, 19(1), 19-27. Recuperado de http://www.sciencedirect.com/science?_ob=MiamiImageURL\&_cid=271951\&_user=687358\& _pii=S0263786399000381\&_check=y\&_origin $=$ search\&_zone=rsit_list_item\&_coverDate $=200$ 1-01-31\&wchp=dGLzVlS-zSkWb\&md5=7c8de3172916f65313ca34b3208acd0a/1-s2.0S0263786399000381-main.pdf. doi: 10.1016/S0263-7863(99)00038-1

Bell, D., Raiffa, H., \& Tversky, A. (Eds.). (1988). Descriptive, normative, and prescriptive interactions in decision making. Cambridge: Cambridge University Press. 
Borges, A. T. (1998). Modelos mentais de eletromagnetismo. Caderno Catarinense de Ensino de Física, 15(1), 7-31. Recuperado de http://www.dfi.ufms.br/prrosa/Pratica_Ens_Fis_II/Texto_III_Tarciso.pdf.

Carvalho, G. S., \& Mingoti, S. A. (2005). Manual do usuário: programas para realização da análise hierárquica [Manual]. Universidade Federal de Minas Gerais, Belo Horizonte, MG.

Chen, Y. (2006). Multiple criteria decision analysis: classification problems and solutions (Tese de doutorado). University of Waterloo, Waterloo, Ontario, Canada. Recuperado de http://uwspace.uwaterloo.ca/bitstream/10012/2892/1/y3chen2006.pdf

Clemen, R. (1995). Making hard decisions: an introduction to decision analysis. Belmont, CA: Duxbury Press.

Corso, K. B., \& Löbler, M. L. (2010). AHP MAKH-ER: validação de um sistema de apoio à decisão para estudar a influência da pressão do tempo e da falta de informação no processo decisório. Produto e Produção, 11(3), 45-58.

Cozby, P. C. (2003). Métodos de pesquisa em ciências do comportamento. São Paulo: Atlas.

Dillon, S. M. (1998, agosto). Descriptive decision making: comparing theory with practice. Anais do Annual Operational Research Society of New Zealand Conference, Auckland, New Zealand, 33.

Druzdzel, M. J., \& Flynn, R. R. (2002). Decision support systems. In A. Kent (Ed.), Encyclopedia of Library and Information Science (pp. 1-15). New York: Marcel Dekker.

Dunegan, K. J. (1995). Image theory: testing the role of image compability in progress decisions. Organizational Behavior and Human Decision Processes, 62(1), 79-86. doi: 10.1006/obhd.1995.1033

Ensslin, L., Montibeller, G. N., \& Noronha, S. M. (2001). Apoio à decisão - metodologias para estruturação de problemas e avaliação multicritério de alternativas. Florianópolis: Insular.

Ericsson, K. A., \& Simon, H. A. (1993). Protocol analysis: verbal reports as data. Cambridge, MA: MIT Press.

Gomes, L. F. A. M. (2007). Teoria da decisão. São Paulo: Thomson Learning.

Gomes, L. F. A. M., Araya, M. C. G., \& Carignano, C. (2004). Tomada de decisões em cenários complexos. São Paulo: Pioneira Thomson Learning.

Handfield, R., Walton, S. V., Sroufe, R., \& Melnyk, S. A. (2002). Applying environmental criteria to supplier assessment: a study in the application of the analytical hierarchy process. European Journal of Operational Research, 141(1), 70-87. doi: 10.1016/S0377-2217(01)00261-2

Hansson, S. O. (1994). Decision theory a brief introduction. Stockholm: Royal Institute of Technology.

Levin, I. P., \& Jasper J. D. (1995). Phased narrowing. A new process tracing method for decision making. Organizational Behavior and Human Decision Processes, 64(1), 1-8.

Liberatore, M. J., \& Nydick, R. L. (2008). The analytic hierarchy process in medical and health care decision making: a literature review. European Journal of Operational Research, 189(1), 194207. Recuperado http://www.sciencedirect.com/science?_ob=MiamiImageURL\&_cid=271700\&_user=687358\& _pii $=$ S0377221707004729\&_check $=y \&$ \&origin $=$ search\&_zone=rsit_list_item\&_coverDate $=200$ 8-08-16\&wchp=dGLzVlk-zSkzS\&md5=93e1785e08b330f47ab3425337684da3/1-s2.0S0377221707004729-main.pdf. doi: 10.1016/j.ejor.2007.05.001 
Löbler, M. L. (2005). Processamento da informação: uma avaliação dos diferentes níveis de conhecimento no processo de decisão (Tese de doutorado). Universidade Federal do Rio Grande do Sul, Porto Alegre, RS, Brasil. Recuperado de http://www.lume.ufrgs.br/bitstream/handle/10183/4732/000459266.pdf?sequence=1

Löbler, M. L. (2006, setembro). A teoria da imagem como explicação para violação do método multicritério de decisão. Anais do Encontro Nacional da Associação Nacional de PósGraduação e Pesquisa em Administração, Salvador, BA, Brasil, 30.

Lohse, G. L., \& Johnson, E. J. (1996). A comparison of two process tracing methods for choice tasks. Organizational Behavior and Human Decision Processes, 68(1), 28-43. doi: 10.1006/obhd.1996.0087

Martel, J.-M. (1999, fevereiro). Multicriterion decision aid: methods and applications. Anais do Annual Conference on Canadian Operational Research Society (CORS), Windsor, Ontario, Canadá, 33.

McMullen, P. R., \& Tarasewich, P. (2000). Selection of notebook personal computers using data envelopment analysis. The Southern Business and Economic Journal, 23(3), 200-214.

Murakami, M. (2003). Decisão estratégica em TI: estudo de caso (Dissertação de mestrado). Universidade de São Paulo, São Paulo, SP, Brasil. Recuperado de http://www.teses.usp.br/teses/disponiveis/12/12139/tde-19112003-200926/pt-br.php

Norman, D. A. (1983). Some observations on mental models. In D. Gentner \& A. L. Stevens (Eds.), Mental Models (pp. 6-14). Hillsdale, NJ: Lawrence Erlbaum.

Özceylan, E. (2010). A decision support system to compare the transportation modes in logistics. International Journal of Lean Thinking, 1(1), 58-83. Recuperado de http://www.thinkinglean.com/articles/vol1/010701m.pdf

Payne, J. W., Bettman, J. R., \& Johnson, E. J. (1993). The adaptive decision maker. Cambridge: University Press.

Rapoport, A. (1994). Problems of normative and descriptive decision theories. Mathematical Social Sciences, 27(1), 31-47. doi: 10.1016/0165-4896(94)00730-6

Reis, E. (2011). Prescrição ou descrição da decisão humana: uma discussão de um modelo subjacente ao SAD (Dissertação de mestrado). Universidade Federal de Santa Maria, Santa Maria, RS, Brasil.

Roy, B. (1996). Multicriteria methodology for decision aiding. Dordrecht: Kluwer Academic Publishers.

Saaty, T. L. (1991). Método de análise hierárquica. São Paulo: Makron Books.

Saaty, T. L. (2008). Decision making with the analytic hierarchy process. International Journal of Services Sciences, 1(1), 83-98. doi: 10.1504/IJSSCI.2008.017590

Sampieri, R. H., Collado, C. F., \& Lucio P. B. (2006). Metodologia de pesquisa. São Paulo: McGrawHill.

Someren, M. W. van, Barnard, Y. F., \& Sandberg, J. A. C. (1994). The think aloud method: a practical guide to modelling cognitive processes. London: Academic Press.

Stanovich, K. E., \& West, R. F. (1999). Discrepancies between normative and descriptive models of decision making and the understanding/acceptance principle. Cognitive Psychology, 38(3), 349385. doi: 10.1006/cogp.1998.0700 
Tversky, A., \& Kahneman, D. (1986). Rational choice and the framing of decisions. Journal of Business, 59(4), 251-278. doi: 10.1086/296365

Vieira, V. A., \& Slongo, L. A. (2006). Uma análise dos atributos importantes no processo de decisão de compra de notebooks utilizando análise fatorial e escalonamento multidimensional. Revista de Administração Mackenzie, 7(4), 35-59. Recuperado de http://www3.mackenzie.br/editora/index.php/RAM/article/view/110/110

Zanakis, S. H., Solomon, A., Wishart, N., \& Dublish, S. (1998). Multi-attribute decision making: a simulation comparison of select methods. European Journal of Operational Research, 107(3), 507-529. doi: 10.1016/S0377-2217(97)00147-1 